\title{
Araştırma Geliştirme (Ar-Ge) Faaliyetleri ile Ekonomik Büyüme İlişkisinin Meta Analiz Yöntemiyle Değerlendirmesi
}

\section{Evaluation of the Relationship between Research Development Activities and Economic Growth with Meta Analysis Method}

Habibe Yaman ${ }^{\mathrm{a}, *}$

${ }^{a}$ Öğretim Görevlisi, Burdur Mehmet Akif Ersoy Üniversitesi, Rektörlük, İstiklal Yerleşkesi 15030, Burdur/Türkiye ORCID: 0000-0002-9212-3264

\section{MAKALE BILGIISI}

\section{Makale Geçmişi:}

Başvuru tarihi: 02 Eylül 2019

Düzeltme tarihi: 04 Nisan 2020

Kabul tarihi: 20 Nisan 2020

\section{Anahtar Kelimeler:}

Araştırma Geliştirme

Ekonomik Büyüme

Meta Analiz
ÖZ

Bu çalışmanın amacı; araştırma geliştirme (Ar-Ge) faaliyetleri ve ekonomik büyüme ilişkisini meta analiz yöntemiyle değerlendirmektir. Çalışmanın kapsamını Ar-Ge ile ekonomik büyümeyi analiz eden ulusal ve uluslararası yayımlanmış makale ve tezler oluşturmaktadır. Bu bağlamda 20072019 yıl aralığı temel ölçüt alınmış Google Scholar, Scopus, YÖK Ulusal Tez Merkezi veri tabanlarında "Ar-Ge, Araştırma Geliştirme, Ekonomik Büyüme" anahtar kelimeleri Türkçe ve İngilizce biçimlerinde taranmıştır. Örneklem büyüklüğü, ortalaması ve standart sapma değerlerini içeren toplamda 8103 gözleme sahip 9 farklı çalışmanın araştırma bulguları CMA (Comprehensive Meta Analysis) programı yardımıyla analiz edilmiştir. Meta analiz sonuçlarında Ar-Ge faaliyetleri ile ekonomik büyüme arasında pozitif ilişki olduğu ve Ar-Ge faaliyetlerinde meydana gelen \% 1'lik bir artışın ekonomik büyümeyi \% 2.634 arttırmakta olduğu saptanmıştır.

\section{ARTICLE INFO}

\section{Article history}

Received 02 September 2019

Received in revised form 04 April 2020

Accepted 20 April 2020

\section{Keywords:}

Research Development

Economic Growth

Meta Analysis

\section{A B S T R ACT}

The purpose of this study is to evaluate the relationship between research development (R\&D) activities and economic growth through meta-analysis. The scope of the study is create national and international published articles and theses that analyzing R\&D and economic growth. In this context, the basic criterion for the 2007-2019 year period was taken and it was screened keywords "R\&D, Research and Development, Economic Growth" as Turkish and English in Google Scholar, Scopus, YÖK National Thesis Center databases. The research findings of 9 different studies with 8103 observations including sample size, mean and standard deviation values were analyzed with the help of CMA (Comprehensive Meta Analysis) program. As a conclusion of Meta Analysis it is found that positive relationship between R\&D activities and economic growth. Additionally it is found that the increase in $\mathrm{R} \& \mathrm{D}$ activities by $1 \%$ has increased economic growth by $2,634 \%$.

\section{Giriş}

Ülkelerin rekabet gücü ve ekonomik gelişmişlik bakımından üstün olma çabasında teknoloji ve verimlilik başat role sahiptir. Ekonomik büyümeyi sürdürülebilir k1lma gayesinde teknoloji ve verimlilik oldukça önemli olsa da bu gelişimi sağlayan esas faktör özünde araştırma geliştirme (Ar-Ge) faaliyetleridir. Neoklasik öğretide dışsal olan unsurların Romer (1990) vd. ${ }^{1}$ katkılarıyla içselleştirilmesi neticesinde bilgi birikimi, teknolojik değişim ve Ar-Ge faaliyetlerine verilen önem derecesi artmış, Ar-Ge faaliyetleri ekonomik büyümenin itici gücü haline gelmiştir. Bu bağlamda konuyu ele alan pek çok çalışma ve analiz yapılmış ve bu çalışmalar teorik açıdan çoğunlukla içsel büyüme modellerine dayandırılmıştır.

\footnotetext{
${ }^{1}$ Lucas (1988). On The Mechanics Of Economic Development, Journal of Monetary Economics 22, 3-42.
}

\footnotetext{
* Sorumlu yazar/Corresponding author.

e-posta: hyaman@mehmetakif.edu.tr
} 
$\mathrm{Bu}$ çalışmada Ar-Ge faaliyetleri ile ekonomik büyüme üzerine yapılmış olan sayısal çalışma bulgularını meta analiz yöntemini kullanarak incelemek ve Ar-Ge faaliyetleri ile ekonomik büyüme ilişkisi hakkında genel bir değerlendirme yapmak amaçlanmaktadır. Bu kapsamda ilk aşamada Ar-Ge faaliyetleri ve ekonomik büyüme teorik açıdan değerlendirilmiş, yapılan literatür taramasına takiben meta analiz uygulanmış ve analiz sonuçlarına yer verilmiştir. Çalışma, Ar-Ge faaliyetleri ile ekonomik büyüme ilişkisini yapılmış çalışmalar üzerinden meta analizi ile araştırmakta ve bu anlamda yazına katkı sunmaktadir.

\section{Teorik Çerçeve}

Araştırma geliştirme (Ar-Ge) terimi hakkında literatürde farklı kavramsal açıklamalar mevcuttur. Jones ve Williams (2000)'a göre Ar-Ge “uzun vadeli verimlilik ve refahın önemli bir belirleyicisi" olarak tasvir edilirken Frascati Kılavuzuna göre; "birimler, kurumlar ve sektörler, özellikle de devlet ile diğer gerçekleştiriciler arasında kayda değer kaynak transferleri içeren bir süreç" şeklinde tanımlanmaktadır (Frascati K1lavuzu, 2002: 21). Ayrica k1lavuzda "insan, kültür ve toplumun bilgisinden oluşan bilgi dăgarcı̆̆ının arttırılması ve bu dă̆arcı̆̆ın yeni uygulamalar tasarlamak üzere kullanılması için sistematik bir temelde yürütülen yaratıcı çalışmalar" olarak ifade edilmektedir (Frascati Kilavuzu, 2002: 30).

İktisadi literatürde 1879'lardaki Neoklasik marjinal devrim öncesinde klasik iktisatçıların en çok ilgilendikleri olgu olan (Doğaner Gönel, 2016: 71) ve pek çok modele konu olan ekonomik büyüme kavramı, kişi başına reel hasıladaki artışları ima etmektedir (Kibritçioğlu, 1998: 1). Ekonomik büyümenin sınırları ise Klasiklere göre nüfus artışı ile kıt kaynakların ilişkiyle belirlenmekte iken Neoklasik iktisat analizinde bu süreç bileşenlerin tümüyle ilgili olup faktörlerin herhangi birindeki bir artış ilgili faktörün marjinal verimliliğine bağlı olarak üretim miktarında artışa sebep olmaktadır (Doğaner Gönel, 2016: 71). Neoklasik büyüme modeli (Solow, 1956; Swan, 1956) ekonomik büyüme sürecinin anlaşılmasında önemli bir konuma sahip olsa da modeldeki eksiklikler içsel büyüme modellerine zemin hazırlamıştır. $\mathrm{Bu}$ süreçte $\mathrm{Ar}-\mathrm{Ge}$, büyüme ve içsel teknolojik gelişime vurgu yapan yaklaşımlar ön plana çıkmış ve eğitim/öğrenme yolu ile beşeri sermayenin büyüme üzerindeki rol ve önemine vurgu yapan Lucas (1988), kamu harcamalarını temel alan Barro (1990), teknolojik gelişmeyi ve Ar-Ge'yi merkeze alan Romer (1990)'in görüşleri önemli katkılar sunmuştur.

Bunlara ek olarak Grossman ve Helpman ile Aighon Howitt gibi düşünürlerin geliştirdiği modeller literatürdeki yerlerini almışlardır (İspiroğlu, \& Kılıç, 2019: 256). Bu kuramlar kapsamında ekonomik büyümenin daha dinamik unsurlara yatırım yapmaktan geçtiği görüşü kabul görmüş, Ar-Ge faaliyetlerinin ekonomik büyüme açısından rolü ve önemi artmıştır (Akıncı \&Sevinç, 2013: 9).

\section{Literatür Taraması}

Ar-Ge faaliyetleri ile ekonomik büyümeyi içeren literatür oldukça zengindir. Fakat bu konuyu ele alan çalışmalar genel bir perspektifte değerlendirildiğinde ortak bir ampirik bulgu elde edilememektedir. Yapılan araştırmalar ise genellikle yöntem olarak panel veri analizi, zaman serisini veya panel veri analizini içeren nedensellik ve eş bütünleşme testlerine dayanmaktadır. Nedenselliği konu alan uygulamalarda; Ar-Ge faaliyetlerinden ekonomik büyümeye doğru nedensellik saptanmış çalışmalar olmakla birlikte (Ör; İğdeli (2019), Algan vd. (2017), Alper (2017), Genç \&Atasoy (2010)), ekonomik büyümeden Ar-Ge faaliyetlerine doğru nedensellik içeren araştırmalar da bulunmaktadır (Ör: Güneş (2019)). Bunların yanı sıra literatürde karşılıklı nedensellik bulgusunun olduğu uygulamalar da mevcuttur (Ör; Gülmez \& Yardımcıoğlu (2012); Hong (2017)). Bazı çalışmalarda ise nedensellik saptanmamıştır (Ör; Doyar (2019); Tuna vd. (2015)). Literatür taraması sonucunda herhangi bir ilişki tespit edilemeyen çalışmalar olsa da (Ör: Tuna vd. (2015) Ar-Ge faaliyetlerinin ekonomik büyümeyi pozitif etkilediği çalışma sonuçlarının daha yaygın olduğu görülmüştür (Ör; Adak (2007), Baykul (2018), Choi \&Yi (2018), Gumus \& Celikay (2015), İspiroğlu \& K1lıç (2019), Kaneva \& Untura (2019), Sokolov- Mladenović, vd. (2016), Szarowská (2016), Ünal (2018), Yazgan \&Yalçınkaya (2018), Yıldırım vd. (2018), orta gelirli ekonomiler için ise Inekwe (2015)). Negatif etkileyen çalışmalara ise rastlanmamıştır (Bkz. Tablo 1).

Bu çalışma Ar-Ge faaliyetleri ile ekonomik büyüme üzerine yapılmış sayısal çalışma bulguları birleştirip uygulanan meta analizi sonuçlarına dayanarak bütünsel yaklaşımla değerlendirme yapmakta ve dolayısıyla yazına katkısı sağlamaktadır. Bilindiği üzere meta-analiz yazın tarama yöntemi olmakla birlikte diğer yazın tarama yöntemlerinden farklı olarak araştırma bulgularının bir araya getirilmesi, bütünleştirilmesi ve analizi sürecinde istatistik yöntemlerini kullanmaktadır (Durlak, 1995'den Akt. Altıntaş, 2017: 334). Birden fazla bulguların bir araya getirilerek araştırmacılara çalışmaların sonuçlarını özetleyen nicel veriler sunmakta (Gedik ve Üstüner, 2017: 44) ve ortak bir kanıya varılabilmesini sağlamaktadır. Araştırma bu açıdan önem arz etmektedir. 
Tablo 1: Literatür Taramas1

\begin{tabular}{|c|c|c|c|c|}
\hline Yazar & Ülke & Dönem & Yöntem & Sonuç \\
\hline Börü \&Çelik (2019) & Türkiye & $2004-2016$ & $\begin{array}{l}\text { Granger nedensellik } \\
\text { analizi }\end{array}$ & $\begin{array}{l}\text { Ar-Ge harcamaları ile ekonomik büyüme } \\
\text { değişkenleri arasında güçlü bir nedensellik } \\
\text { iliş̧isi saptanmıştır. }\end{array}$ \\
\hline Doyar (2019) & Kanada & $1981-2014$ & $\begin{array}{l}\text { Bootsrap nedensellik } \\
\text { analizi }\end{array}$ & Ekonomik büyüme Ar-Ge'nin nedeni değildir. \\
\hline Güneş (2019) & $\begin{array}{l}32 \text { OECD } \\
\text { ülkesi }\end{array}$ & $2000-2014$ & Panel veri analizi & Ekonomik büyüme $\rightarrow$ Ar-Ge \\
\hline İğdeli (2019) & Türkiye & $1990-2016$ & $\begin{array}{l}\text { ARDL yöntemi ve } \\
\text { Granger Nedensellik } \\
\text { testi }\end{array}$ & $\mathrm{Ar}-\mathrm{Ge} \rightarrow$ ekonomik büyüme \\
\hline $\begin{array}{l}\text { İspiroğlu \&Kılıç } \\
\quad \text { (2019) }\end{array}$ & $\begin{array}{l}15 \text { yükselen } \\
\text { piyasa } \\
\text { ekonomisi }\end{array}$ & $1996-2015$ & Panel veri analizi & Ar-Ge harcamaları $\rightarrow$ ekonomik büyüme $(+)$ \\
\hline $\begin{array}{l}\text { Kaneva \& Untura } \\
\text { (2019) }\end{array}$ & Rusya & $2005-2013$ & $\begin{array}{l}\text { Dinamik panel veri } \\
\text { analizi- GMM }\end{array}$ & $\begin{array}{l}\text { Ar-Ge } \rightarrow \text { kişi başı ekonomik büyüme (+ ve } \\
\text { anlamlı) }\end{array}$ \\
\hline Song vd. (2019) & Çin & $2005-2015$ & Panel veri analizi & $\begin{array}{l}\text { Ar-Ge yatırımı yeşil ekonomik büyüme } \\
\text { üzerinde olumlu bir etkiye sahiptir. }\end{array}$ \\
\hline Baykul (2018) & Türkiye & 2010-2014 & Panel veri analizi & Ar-Ge $\rightarrow$ ekonomik büyüme $(+)$ \\
\hline Choi \&Yi (2018) & 105 ülke & 1994-2014 & Panel veri analizi & Ar-Ge harcamaları $\rightarrow$ ekonomik büyüme $(+)$ \\
\hline Liu \& Xia (2018) & Çin & $1995-2016$ & $\begin{array}{l}\text { VAR (Vektör } \\
\text { Otoregresyon } \\
\text { Modeli) analizi }\end{array}$ & $\begin{array}{l}\text { Çalışmada sonucunda Ar-Ge yatırımı, } \\
\text { teknolojik yenilikçilik ve ekonomik büyüme } \\
\text { arasında iyi bir döngüsel mekanizma } \\
\text { kurulmamıştır. }\end{array}$ \\
\hline Ünal (2018) & $\begin{array}{l}21 \text { OECD } \\
\text { ülkesi }\end{array}$ & $1993-2014$ & Panel ARDL analizi & $\begin{array}{l}\text { Uzun dönem için: Ar-Ge harcamaları } \rightarrow \\
\text { ekonomik büyüme }(+)\end{array}$ \\
\hline $\begin{array}{c}\text { Yazgan } \\
\text { \&Yalçınkaya (2018) }\end{array}$ & OECD ülkeleri & $1996-2015$ & Panel veri analizi & $\begin{array}{l}\text { Ar-Ge yatırım değişkenleri } \rightarrow \text { ekonomik } \\
\text { büyüme }(+)\end{array}$ \\
\hline Yildirım vd. (2018) & $\begin{array}{l}\text { G-20 } \\
\text { ülkelerinden } \\
13 \text { ülke }\end{array}$ & $1996-2014$ & Panel veri analizi & Ar-Ge harcamaları $\rightarrow$ büyüme $(+)$ \\
\hline Alper (2017) & Türkiye & $1990-2015$ & $\begin{array}{c}\text { Bayer-Hanck } \\
\text { eşbütünleşme analizi }\end{array}$ & $\begin{array}{l}\text { Nedenselliğin yönü: Ar-Ge harcamaları } \rightarrow \\
\text { büyüme }\end{array}$ \\
\hline Algan vd. (2017) & Türkiye & $1996-2015$ & $\begin{array}{l}\text { Granger nedensellik } \\
\text { analizi }\end{array}$ & $\begin{array}{l}\text { Nedenselliğin yönü: Ar-Ge harcamaları } \rightarrow \\
\text { büyüme }\end{array}$ \\
\hline Hong (2017) & Kore & $1988-2013$ & $\begin{array}{l}\text { Granger nedensellik } \\
\text { analizi }\end{array}$ & $\begin{array}{l}\text { Ekonomik büyüme ile BİT (Bilgi ve İletişim } \\
\text { Teknolojileri)'e yapılan Ar-Ge yatırımı } \\
\text { arasında çift taraflı nedensellik saptanmıştır. }\end{array}$ \\
\hline $\begin{array}{l}\text { Freimane \& Bāliņa } \\
\qquad(2016)\end{array}$ & $\mathrm{AB}$ ülkeleri & $2000-2013$ & Panel veri analizi & $\mathrm{Ar}-\mathrm{Ge} \rightarrow$ ekonomik büyüme (anlamlı) \\
\hline $\begin{array}{l}\text { Sokolov- } \\
\text { Mladenović, vd. } \\
\text { (2016) }\end{array}$ & 28 AB ülkesi & 2002-2012 & $\begin{array}{l}\text { Sabit etkili çoklu } \\
\text { regresyon modeli }\end{array}$ & $\begin{array}{l}\text { Ar-Ge harcamaların }(\mathrm{GSYH} \%) \rightarrow \text { reel } \\
\text { büyüme oranı }(+)\end{array}$ \\
\hline Sun vd. (2016) & $\begin{array}{l}23 \text { OECD } \\
\text { ülkesi }\end{array}$ & $1996-2010$ & Veri zarflama analizi & Ar-Ge yatırımları $\rightarrow$ verimlilik $(+)$ \\
\hline Szarowská (2016) & 20 AB ülkesi & $1995-2013$ & $\begin{array}{l}\text { Dinamik panel veri } \\
\text { analizi- GMM } \\
\text { (Genelleştirilmiş } \\
\text { moment yöntemi) }\end{array}$ & $\begin{array}{l}\text { Ekonomik büyümenin temel etmeni olan } \\
\text { kamu Ar-Ge harca-malarının olumlu ve } \\
\text { istatistiksel olarak önemli bir etkisi vardır. }\end{array}$ \\
\hline $\begin{array}{c}\text { Gumus \& Celikay } \\
\qquad(2015)\end{array}$ & 52 ülke & $1996-2010$ & $\begin{array}{l}\text { Dinamik panel veri } \\
\text { analizi }\end{array}$ & $\begin{array}{l}\text { Uzun dönem tüm ülkeler için: Ar-Ge } \\
\text { harcamaları } \rightarrow \text { ekonomik büyüme }(+ \text { ve } \\
\text { anlamlı) }\end{array}$ \\
\hline Inekwe (2015) & $\begin{array}{l}\text { Gelişmekte } \\
\text { olan } \\
\text { ekonomiler } \\
\text { (66 ülke) }\end{array}$ & 2000-2009 & $\begin{array}{l}\text { Dinamik panel veri } \\
\text { analizi - GMM }\end{array}$ & $\begin{array}{l}\text { Orta gelirli ekonomilerde: Ar-Ge harcamaları } \\
\rightarrow \text { ekonomik büyüme }(+) \\
\text { Düşük gelirli ekonomilerde: önemsiz düzey }\end{array}$ \\
\hline Kokko vd. (2015) & 49 ülke & - & Meta analiz & Ar-Ge $\rightarrow$ ekonomik büyüme $(+)$ \\
\hline Tuna vd. (2015) & Türkiye & $1990-2013$ & $\begin{array}{l}\text { Granger nedensellik } \\
\text { analizi }\end{array}$ & $\begin{array}{l}\text { Ar-Ge harcamaları } \neq \text { ekonomik büyüme } \\
\text { (nedensellik yoktur). }\end{array}$ \\
\hline $\begin{array}{l}\text { Gülmez \& } \\
\text { Yardımcioğlu } \\
\text { (2012) }\end{array}$ & $\begin{array}{l}21 \text { OECD } \\
\text { ülkesi }\end{array}$ & $1990-2010$ & $\begin{array}{l}\text { Panel eşbütünleşme } \\
\text { ve panel nedensellik } \\
\text { analizi }\end{array}$ & $\begin{array}{l}\text { Ar-Ge harcamaları } \leftrightarrow \text { ekonomik büyüme }( \\
\text { uzun dönem anlamlı) }\end{array}$ \\
\hline $\begin{array}{l}\text { Genç \&Atasoy } \\
\text { (2010) }\end{array}$ & 34 ülke & $1997-2008$ & $\begin{array}{l}\text { Panel nedensellik } \\
\text { analizi }\end{array}$ & $\begin{array}{l}\text { Ar-Ge harcamaları } \rightarrow \text { ekonomik büyüme } \\
\text { (tek yönlü nedensellik) }\end{array}$ \\
\hline Adak (2007) & $\begin{array}{l}15 \text { OECD } \\
\text { ülkesi }\end{array}$ & $1990-2004$ & Panel veri analizi & Ar-Ge $\rightarrow$ ekonomik büyüme $(+)$ \\
\hline
\end{tabular}




\section{Meta Analiz}

Çalışmanın temel amacı; Ar-Ge faaliyetleri ile ekonomik büyüme üzerine yapılmış olan sayısal çalışma bulgularını analiz ederek Ar-Ge faaliyetleri ile ekonomik büyüme ilişkisi üzerine genel bir sonuç ortaya koymaktır. Bu bağlamda çalışma modelinde temel hipotez şu şekilde oluşturulmuştur: ${ }^{2}$

$$
\begin{aligned}
& \mathrm{H}_{0}: \mathcal{\varepsilon} \neq f(r d) \\
& \mathrm{H}_{1}: \mathcal{E}=f(r d)
\end{aligned}
$$

Bilindiği üzere meta-analizi, "belirli bir konuda yapılmış birbirinden bağımsız birden çok çalışmanın sonuçların birleştirme ve elde edilen araştırma bulgularının istatistiksel analizini yapma yöntemidir" (Akgöz \& Kan, 2004: 107). Araştırma çıktılarını incelenmemiş yeni parametrelerle inceleyebilmekte, yeni ilişkileri ortaya çıkartabilmekte ve yapılacak araştırmalara farklı bakış açıları getirebilmektedir (Deliktaş vd. 2016: 1906). Bu bağlamda yöntem olarak meta analiz tercih edilmiş, CMA 3.0 (Comprehensive Meta Analysis Version 3.0) programı kullanılmıştır. Araştırma sonuçlarının doğruluğu ve uygun modelin seçimi için homojenlik analizi yapılmış, uygun model Hedges's g testi ile seçilmiştir. Meta analiz çalışmasında yayım yanlılığı Trim ve Fill testi ile kontrol edilip araştırma güvenirliği ise Klasik Güvenli N (Classic Fail-Safe N) analizi ile sağlanmıştır. Böylece yayın yanlılığının olup olmadığı ve etki büyüklük değerlerinin doğruluğu kontrol edilmiş̧ir.

\subsection{Veri Seti ve Meta Analiz Ölçütleri}

Meta-analiz uygulaması; araştırma konusunun, soruların, ölçütlerin belirlenmesini ve elde edilen makalelerin sınıflanmasını, elenmesini, kodlanması, çalışmaların kalitesinin değerlendirilerek analizlerin yapılıp sonuçlarının raporlanmasını içeren bir süreçtir. Analiz sürecinde uygun çalışmaların belirlenmesi zor ve zaman alıııdır. Ayrıca, analiz için uygun olmayan çalışmaların varlı̆̆ı sebebiyle tüm çalışmaların dâhili de mümkün değildir (Deliktaş vd. 2016: 1907). Bu yüzden meta analiz için araştırılması gereken olgunun net bir biçimde ortaya konulabilmesi gereklidir. Bu kapsamda çalışmada beş ölçüt kullanılmıştır (Bkz. Tablo 2). İlk ölçüt olarak çalışmanın 2007-2019 yılları arasında yayımlanmış olması dikkate alınmıştır. İkinci aşamada ise çalışma biçiminin "ulusal ve uluslararası yayımlanmış makale veya tez olmasına" karar verilmiş ve Google Scholar, Scopus, YÖK Ulusal Tez Merkezi veri tabanlarında konu ile ilgili anahtar kavramlar Türkçe ve İngilizce karşılıklarıyla taranmıştır. Bu kapsamda ilk etapta 89 yayın incelemeye alınmıştır. Sonrasında örneklem büyüklügü, ortalama ve standart sapması bulunması kriteri dikkate alınmış ve bu çalışmalardan beşinci ölçütü yalnızca 9 çalışma sağlamıştır. Dolayısıyla analize toplamda 8103 gözleme sahip 9 çalışma dâhil edilebilmiştir.

\footnotetext{
${ }^{2} \mathrm{H}_{0}$ hipotezi Ar-Ge faaliyetlerinin ekonomik büyüme üzerinde etkisi olmadığını, $\mathrm{H}_{1}$ hipotezi ise olduğunu ifade etmektedir.
}

\begin{tabular}{|c|c|c|}
\hline & Gerekli Ölçüt & Alınan Ölçüt \\
\hline 1 & Zaman Aralığ 1 & 2007-2019 yıl aralığı \\
\hline 2 & $\begin{array}{l}\text { Çalışmalar } \\
(\text { makale/tez/...) }\end{array}$ & $\begin{array}{l}\text { Ulusal ve uluslararası yayımlanmış } \\
\text { makale ve tezler }\end{array}$ \\
\hline 3 & Veri Tabanı & $\begin{array}{l}\text { "Google Scholar, Scopus, YÖK Ulusal } \\
\text { Tez Merkezi” veri tabanında yayımlanmış } \\
\text { çalışmalar }\end{array}$ \\
\hline 4 & Taranan Kavram & $\begin{array}{l}\text { Ar-Ge, Araştırma Geliştirme, Ekonomik } \\
\text { Büyüme, Ar-Ge (Araştırma Geliştirme) } \\
\text { ve/ile Ekonomik Büyüme, Ar-Ge } \\
\text { (Araştırma Geliştirme) Büyüme İlişkisi }\end{array}$ \\
\hline 5 & $\begin{array}{l}\text { Çalışmaya Dâhil } \\
\text { Etme Kriteri }\end{array}$ & $\begin{array}{l}\text { Veri setinde örneklem büyüklüğü, } \\
\text { ortalama ve standart sapması bulunan } \\
\text { çalışmalar }\end{array}$ \\
\hline
\end{tabular}

Tablo 2: Analiz Ölçütleri

Meta analize dâhil edilen çalışmaların ikisi tez, yedisi makale olmakla birlikte makalelerin üçü Google Scholar, dördü Scopus, tezlerin ikisi de YÖK Ulusal Tez Merkezi veri tabanından alınmıştır. Veri setine ilişkin ilgili kodlama ve dağılım Tablo 3'de verilmiş ve bu çalışmalar kaynaklar bölümünde * ile gösterilmiştir.

\begin{tabular}{cccc} 
Tablo 3: Veri Seti & & \\
\hline Kod & Endeks & $\begin{array}{c}\text { Yayın } \\
\text { say1s1 }\end{array}$ & Y11 \\
\hline $\mathrm{G}_{1}$ & Google Scholar & 1 & 2010 \\
$\mathrm{G}_{2}$ & Google Scholar & 1 & 2018 \\
$\mathrm{G}_{3}$ & Google Scholar & 1 & 2018 \\
$\mathrm{~S}_{1}$ & Scopus & 1 & 2019 \\
$\mathrm{~S}_{2}$ & Scopus & 1 & 2019 \\
$\mathrm{~S}_{3}$ & Scopus & 1 & 2016 \\
$\mathrm{~S}_{4}$ & Scopus & 1 & 2017 \\
$\mathrm{~T}_{1}$ & YÖK Ulusal Tez Merkezi & 1 & 2007 \\
$\mathrm{~T}_{2}$ & YÖK Ulusal Tez Merkezi & 1 & 2018 \\
Toplam & Makale & 7 & Obs: 8103 \\
\multicolumn{4}{c}{ Tez } \\
\hline
\end{tabular}

*Obs gözlem sayısın ifade etmektedir.

\section{2. Araștırma Bulguları}

Meta analiz için toplanan veri setinin gösterdiği etki büyüklüklerinden elde edilen değerlerin tüm popülasyonun etki büyüklüğüne ait bilgileri içerip içermediği homojenlik analizi ile test edilmelidir (Bakioğlu \& Özcan, 2016: 160). Çalışmada öncelikle araştırma geliştirme ile ekonomik büyüme arasındaki genel etkiyi saptamak için homojenlik testi yapılmıştır.

\begin{tabular}{|c|c|c|c|c|}
\hline \multicolumn{5}{|c|}{ Etki Büyüklüğ̈̈ ve \%95 güven aralı̆g } \\
\hline \multirow[t]{2}{*}{ Model } & Çalışma & Nokta & Alt & Üst \\
\hline & say1s1 & tahmini & Limit & Limit \\
\hline Sabit & 9 & 0.651 & 0.602 & 0.701 \\
\hline Rassal & 9 & 2.638 & 1.571 & 3.704 \\
\hline \multirow[t]{2}{*}{ Heterojenlik } & & Q-Değeri & $\operatorname{df}(Q)$ & p- \\
\hline & & 3033.626 & 8 & $0.000 *$ \\
\hline
\end{tabular}

Tablo 4: Homojenlik Test Sonuçları

Meta-analizde sıklıkla kullanılan temelde iki model var olup bunlar: "sabit etkiler modeli ve rastgele etkiler modelidir" (Deliktaş vd. 2016: 1916). Sabit etkiler modeli temelde meta analiz araştırmasında yer alan çalışmaların tam olarak aynı etki büyüklük değerine sahip olduğunu 
varsayarken rastgele etkiler modelinde etki büyüklüklerinin farklı olduğu varsayılmaktadır (Bakioğlu \& Özcan, 2016: $165)$.

Meta analizde homojenlik test sonucu, model seçiminde belirleyicidir. Homojenlik test sonucunda bireysel çalışma sonuçlarının homojenliği söz konusu iken sabit etkiler modelinin, heterojenlik söz konusu iken rastgele etkiler modelinin kullanılması gerekmektedir (Dinçer, 2014: 19). Dolayısıyla bu çalışmada meta analize dâhil olan çalışmaların etki değerleri farklıdır ve Hedges's g testi sonuçlarına göre rastgele etkiler modeli geçerlidir.

Rastgele etkiler modeli sonuçlarına göre ise çalışmalar dengeli bir dağılım göstermiş olmakla birlikte ele alınan çalışmaların oranlaması Tablo 5'de gösterilmiştir.

Tablo 5: Çalışma Dağglımı

\begin{tabular}{cc}
\hline Çalışma & Yüzde $(\%)$ \\
\hline $\mathrm{G}_{1}$ & 11.37 \\
$\mathrm{G}_{2}$ & 11.35 \\
$\mathrm{G}_{3}$ & 11.22 \\
$\mathrm{~S}_{1}$ & 11.05 \\
$\mathrm{~S}_{2}$ & 11.38 \\
$\mathrm{~S}_{3}$ & 11.30 \\
$\mathrm{~S}_{4}$ & 11.39 \\
$\mathrm{~T}_{1}$ & 9.56 \\
$\mathrm{~T}_{2}$ & 11.37 \\
\hline
\end{tabular}

Araştırma geliştirme faaliyetleri ile ekonomik büyüme arasındaki genel korelasyon ise sabit etkilere göre 0.519 iken rastgele etkilere göre 0.491 'dir (Bkz. Tablo 6).

Tablo 6: Genel Korelasyon Sonuçları

\begin{tabular}{lc}
\hline & Korelasyon Katsayıs1 \\
\hline Sabit Etkiler & 0.519 \\
Rastgele Etkiler & 0.491 \\
\hline
\end{tabular}

Meta-analize dâhil edilen bireysel çalıșmaların genel etki büyüklükleri birbirinden farklıdır. İki sürekli değişken arasındaki ilişkiyi ele alan meta analiz çalışmalarında etki büyüklüklerini görmek için Fisher tarafından geliştirilen bir analiz olan Fisher-z dönüşümü sıklıkla kullanılmaktadır (Lipsey \& Wilson, 2001'den Akt. Bond vd. 2004: 291; Türesin Tetik vd. 2018: 300). Fisher-z analizine göre en yüksek bireysel etki T1 çalışmasına aittir. Bireysel çalışmaların genel etki büyüklükleri Tablo 7'de verilmiştir.

Tablo 7: Meta-Analize Dâhil Edilen Bireysel Çalışmaların Genel Etki Büyüklükleri

\begin{tabular}{ccc}
\hline Kod & Fisher's Z & Std. Hata \\
\hline $\mathrm{G}_{1}$ & 0.003 & 0.037 \\
$\mathrm{G}_{2}$ & 0.523 & 0.042 \\
$\mathrm{G}_{3}$ & -0.588 & 0.085 \\
$\mathrm{~S}_{1}$ & 2.287 & 0.029 \\
$\mathrm{~S}_{2}$ & 0.438 & 0.025 \\
$\mathrm{~S}_{3}$ & -1.502 & 0.031 \\
$\mathrm{~S}_{4}$ & 0.390 & 0.018 \\
$\mathrm{~T}_{1}$ & 2.927 & 0.038 \\
$\mathrm{~T}_{2}$ & 0.357 & 0.032 \\
$\mathrm{Re}$ & 0.538 & 0.411 \\
$\mathrm{Fe}$ & 0.575 & 0.010 \\
\hline
\end{tabular}

Fisher's Z değerlerinde rastgele etkiler modeline göre araştırma geliştirme faaliyetleri ile ekonomik büyüme arasında pozitif ve güçlü ${ }^{3} \quad(0.575)$ bir ilişki öngörülmektedir.

Bazı çalışmalarda istatistiksel olarak anlamlı ilişkiler tespit edilememekte ya da düşük seviyede tespit edildiğinden çalışmalar yayımlanmaya değer görülmemektedir. $\mathrm{Bu}$ durum toplam etkinin yanlı şekilde artmasına neden olmaktadır (Karadağ vd. 2016: 114). Bu husus meta analiz çalışmalarında toplam etkiyi olumsuz etkileyen kayıp veri de denilen yayım yanlılığ k1lmaktadır.

Çalışmada yayım yanlılı̆̆ Trim ve Fill testi ile test edilmiş ve test sonucunda sanal etki büyüklüğü arasında fark olmadığı, yani çalışmada yayım yanlılığı olmadığı saptanmış, test sonuçları Tablo 8 'de verilmiştir.

Tablo 8: Yayım Yanlılığı Sonuçları

\begin{tabular}{ccccc}
\hline & \multicolumn{4}{c}{ Sabit Etkiler } \\
\hline & $\begin{array}{c}\text { Çıkartılmış } \\
\text { Çalışma }\end{array}$ & $\begin{array}{c}\text { Nokta } \\
\text { Tahmini }\end{array}$ & Alt Limit & Üst Limit \\
$\mathrm{G}$ & & 0.65055 & 0.60090 & 0.70019 \\
$\mathrm{D}$ & 0 & 0.65055 & 0.60090 & 0.70019 \\
\hline \multicolumn{4}{c}{ Rastgele Etkiler } \\
\hline & Nokta & Alt Limit & Üst Limit & Q Değeri \\
& Tahmini & & & \\
$\mathrm{G}$ & 2.63438 & 1.56889 & 3.69987 & 3033.62599 \\
$\mathrm{D}$ & 2.63438 & 1.56889 & 3.69987 & 3033.62599 \\
\hline
\end{tabular}

Not: G: Gözlenen değer D: Düzeltilmiş dĕgeri ifade etmektedir.

Etki büyüklüğünü içeren değerlerinin doğruluğunu saptamak amacıyla Klasik Güvenli N (Classic Fail-Safe N) analizi yapılmıştır (Bkz. Tablo 9).

Tablo 9: Klasik Güvenli N Analizi

\begin{tabular}{lc}
\hline & Katsay1 \\
\hline $\mathrm{Z}$ değeri & 28.017 \\
$\mathrm{p}$-değeri & 0.000 \\
Alfa değeri & 0.050 \\
Alfa değeri için Z değeri & 1.959 \\
$\mathrm{~N}$ & 9 \\
$\mathrm{p}>$ alfa sonucu için gerekli çalışma sayısı & 1831 \\
\hline
\end{tabular}

P-değerinin alfa değerinden küçük olması (P değeri: $0.00<0.05)$ uygulanan meta-analizin bulgular için güvenilir ve güçlü olduğunun göstergesi olarak kabul edilmektedir (Dağyar \& Kasalak, 2018: 974). N analizi sonuçlarına bakıldığında yapılan meta analizi geçersiz kılmak için 1831 çalışma yapılmasına ihtiyaç vardır. Bu sonuç da özünde meta analiz çalışmasında yayın yanlılığı olmadığını göstermektedir.

İncelenen çalışma bulguları dikkate alınarak yapılan meta analiz sonucunda araştırma geliştirme faaliyetleri ve ekonomik büyüme arasındaki ilişkinin pozitif olduğu saptanmış, meta analiz çalışması bulguları Tablo 10'da verilmiştir.

\footnotetext{
${ }^{3}$ Cohen vd. (2007)' e göre korelasyon katsayısı (etki büyüklüğü) şöyle yorumlanır: $(<0+/-0.1)$ zayıf, $(0+/-0.3)$ 1lımlı, $(<0+/-0.5)$ orta, $(<$ $0+/-0.8)$ güçlü, $(\geq+/-0.8)$ çok güçlü (Cohen, Manion ve Marrison, 2007, s. 521).
} 
Tablo 10: Meta Analiz Sonuçları

\begin{tabular}{llllllll}
\hline & $\begin{array}{l}\text { Hedge } \\
\text { s’s G }\end{array}$ & $\begin{array}{l}\text { Std. } \\
\text { hata }\end{array}$ & $\begin{array}{l}\text { varya } \\
\text { ns }\end{array}$ & $\begin{array}{l}\text { Alt } \\
\text { limit }\end{array}$ & $\begin{array}{l}\text { Üst } \\
\text { limit }\end{array}$ & Z-değ. & $\begin{array}{l}\mathrm{P}- \\
\text { değ. }\end{array}$ \\
\hline $\mathrm{G}_{1}$ & 0.007 & 0.075 & 0.006 & - & 0.153 & 0.092 & 0.927 \\
& & & & 0.139 & & & \\
$\mathrm{G}_{2}$ & 1.093 & 0.096 & 0.009 & 0.904 & 1.282 & 11.346 & 0.000 \\
$\mathrm{G}_{3}$ & -1.237 & 0.198 & 0.039 & - & - & -6.240 & 0.000 \\
& & & & 1.625 & 0.848 & & \\
$\mathrm{~S}_{1}$ & 9.734 & 0.284 & 0.081 & 9.178 & 10.29 & 34.306 & 0.000 \\
& & & & & 1 & & \\
$\mathrm{~S}_{2}$ & 0.903 & 0.055 & 0.003 & 0.794 & 1.011 & 16.326 & 0.000 \\
$\mathrm{~S}_{3}$ & -4.292 & 0.146 & 0.021 & - & - & -29.257 & 0.000 \\
& & & & 4.548 & 3.976 & & \\
$\mathrm{~S}_{4}$ & 0.805 & 0.040 & 0.002 & 0.728 & 0.883 & 20.378 & 0.000 \\
$\mathrm{~T}_{1}$ & 18.581 & 0.704 & 0.496 & 17.20 & 19.96 & 26.381 & 0.000 \\
& & & & 0 & 1 & & \\
$\mathrm{~T}_{2}$ & 0.728 & 0.068 & 0.005 & 0.595 & 0.861 & 10.720 & 0.000 \\
$\mathrm{Re}$ & 2.634 & 0.544 & 0.296 & 1.569 & 3.700 & 4.846 & 0.000 \\
\hline
\end{tabular}

Rastgele etkiler modeli sonuçlarına göre $\mathrm{P}-$ değeri: $0.00<0.05$ olduğundan Ar-Ge faaliyetlerinin ekonomik büyüme üzerinde etkisinin olmadığını ifade eden $\mathrm{H}_{0}$ hipotezi ret edilip $\mathrm{H}_{1}$ hipotezi kabul edilir. Meta analiz sonuçlarına göre rastgele etkiler modelinde Ar-Ge faaliyetlerindeki \%1'lik bir artış ekonomik büyümeyi \% 2.634 oranında arttırmaktadır. Her ne kadar yöntem bakımından farklılıklar bulunsa da elde edilen bu sonuç artış yönü ve işareti bakımından literatürdeki İspiroğlu \& Kılıç (2019), Kaneva \& Untura (2019), Baykul (2018), Choi \& Yi (2018), Ünal (2018), Yazgan \& Yalçınkaya (2018), Y1ldırım vd. (2018), Sokolov-Mladenović, vd. (2016), Gumus \& Celikay (2015), Inekwe (2015), Kokko vd. (2015), Adak (2007) çalışma sonuçlarıyla örtüşmektedir.

Meta analize dâhil edilen çalışma sayısının az ve çalışmaların \%95 güven aralığı değerlerinin çok geniş olması yanlış bulgulara yol açmaktadır (Kılıçkap, 2018: 629). Meta analiz sonuçlarında ilgili çalışmaların etki büyüklüklerine ilişkin grafiksel sunum hata- kabarcık grafiği ile Şekil 1'de gösterilmiştir. Yapılan analiz sonucunda güven aralığı değerlerinin yanlış yorumlara yol açmayacak derecede çok geniş bir dağılım göstermediği görülmektedir.

Hedpeors gund 95s CI

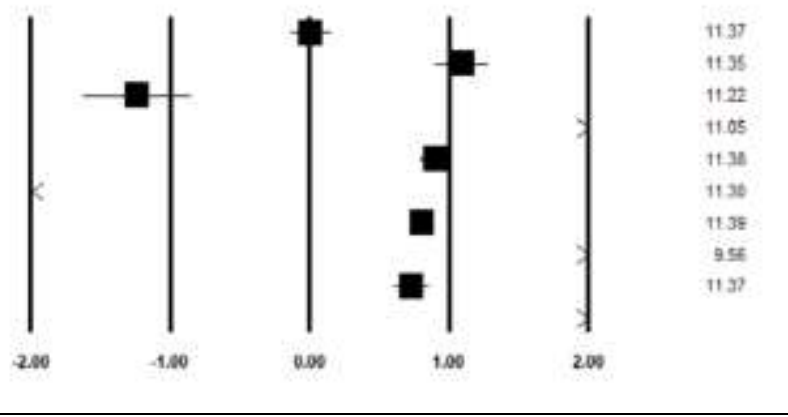

Şekil 1: Meta Analiz Hata- Kabarcık Grafiğgi Not: Çizgi uzunlukları güven aralıklarını ifade etmektedir.

\section{Sonuç}

Bu çalışmada Ar-Ge faaliyetleri ile ekonomik büyüme ilişkisini meta analiz yöntemini kullanarak incelemek ve Ar-Ge faaliyetleri ile ekonomik büyüme ilişkisi hakkında genel bir değerlendirme yapmak amaçlanmıştır. Araştırma kapsamında Google Scholar, Scopus, YÖK Ulusal Tez Merkezi veri tabanından alınan 2007-2019 yıl aralığında yayımlanmış, veri setinde örneklem büyüklüğü, ortalama ve standart sapması bulunan 8103 gözleme sahip toplamda 9 sayısal çalışmanın bulguları birleştirip meta analizi uygulanmış, sonuçlarına dayanarak bütünsel yaklaşımla değerlendirme yapılmıştır. Meta analiz bulguları maddeler halinde özetlenmiştir.

i. Meta analiz için toplanan veri setinin gösterdiğ etki büyüklüklerinden elde edilen değerlerin tüm popülasyonun etki büyüklüğüne ait bilgileri içerip içermediğini görmek ve model seçimi yapmak için yapilan homojenlik testi sonucunda; meta analize dâhil olan çalışmaların etki büyüklükleri farklı olduğu ve Hedges's g testi sonuçlarına göre rastgele etkiler modeli geçerli olduğu saptanmıştır.

ii. Meta-analiz uygulamasına dâhil edilen bireysel çalışmaların genel etki büyüklüğünü hesaplamak için kullanılan Fisher-z dönüşümü sonucunda araştırma geliştirme faaliyetleri ve ekonomik büyüme arasındaki ilişkinin güçlü ve pozitif olduğu ön görülmüştür.

iii. Çalışmanın güvenilirliğini sağlamak için yayım yanlılığı Trim ve Fill testi ile test edilmiş ve etki büyüklüğünü içeren değerlerinin doğruluğunu saptamak ve kanıtlayabilmek için Klasik Güvenli $\mathrm{N}$ analizi uygulanmıştır. Trim ve Fill testi sonucunda yayım yanlılığı olmadığı, Klasik Güvenli $\mathrm{N}$ analizi sonucunda ise yapilan meta analizi geçersiz kılmak için Ar-Ge faaliyetleri ile ekonomik büyüme ilişkisini araştıran 1831 çalışmanın analize eklenmesi gerektiği saptanmıştır. Elde edilen bulgular meta-analiz çalışmasının güçlü ve güvenilir olduğunu ortaya koymaktadir.

iv. Meta analiz sonuçlarında ise Ar-Ge faaliyetleri ile ekonomik büyüme arasında pozitif yönlü ilişki olduğu ve Ar-Ge faaliyetlerinde meydana gelen \%1'lik bir artışın ekonomik büyümeyi \% 2.634 arttırmakta olduğu saptanmıştır.

Meta analiz sonuçları neticesinde saptanan ekonomik büyüme ile Ar-Ge faaliyetleri arasındaki güçlü bağ sebebiyle ekonomik büyüme için Ar-Ge faaliyetlerine daha fazla önem verilmesi gerektiği söylenebilir. Araştırmanın, daha fazla sayıda çalışmayı analize dâhil ederek değişik ölçütlerle uygulanması mümkün olmakla birlikte konu ile ilgili yapılacak yeni araştırmalara yol göstereceği düşünülmektedir.

\section{Kaynaklar}

Meta analize dâhil edilen çalışmalar * ile gösterilmiştir.

*Adak, M. (2007). Ar-Ge \& Ekonomik Büyüme, Marmara Üniversitesi Sosyal Bilimler Enstitüsü, İktisat Anabilim Dalı, İktisat Teorisi Bilim Dalı, Doktora Tezi, İstanbul. 
Akgöz, S., Ercan, İ. ve Kan, İ. (2004). Meta-analizi, Uludăg Üniversitesi Tıp Fakültesi Dergisi, 30(2), 107-112.

Akıncı ve Sevinç (2013). Ar\&Ge Harcamaları İle Ekonomik Büyüme Arasındaki İlişki: 1990-2011 Türkiye Örneği, Uluslararası Sosyal Araştırmalar Dergisi, 6(27), 7-17.

Algan, N., Manga, M. ve Tekeoğlu, M. (2017). Teknolojik Gelişme Göstergeleri ile Ekonomik Büyüme Arasındaki Nedensellik İlişkisi: Türkiye Örneği, International Conference On Eurasian Economies, 332-338.

Alper, A. E. (2017). Türkiye'de Patent, Ar-Ge Harcamaları, İhracat ve Ekonomik Büyüme Arasındaki İlişki: Bayer-Hanck Eş Bütünleşme Analizi, 3nd International Congress on Political, Economic and Social Studies (ICPESS), 17-26.

Altıntaş, F.Ç. (2017), Örgütsel Adalet İle İş Tatmini Arasındaki İlişki Üzerine Bir Meta - Analiz Çalışması, International Journal of Academic Value Studies, 3(9), 332-343.

Bakioğlu, A. ve Özcan, Ş. (2016). Meta Analiz, 1. Basım, Ankara: Nobel Akademik Yayıncılık.

Barro, Robert J. 1990. Government Spending In A Simple Model Of Endogeneous Growth, Journal of Political Economy, 98(S5): 103-125.

*Baykul, A. (2018). Bölgesel Ekonomik Büyüme Üzerinde Ar-Ge Faaliyetlerinin Etkileri: Türkiye'de Düzey I Bölgelerinde Ampirik Bir İnceleme, MANAS Sosyal Araştırmalar Dergisi, 7(2), 113-154.

Bond, C. F. and Richardson, K. (2004). Seeing The Fisher Z-Transformation, Psychometrika, 69(2), 291-303.

Börü, M. ve Çelik, D. (2019). Türkiye'de Ar-Ge Harcamalar1, İnovasyon ve Ekonomik Büyüme İlişkisi, R\&S - Research Studies Anatolia Journal, 2(5), 196-206; DOI: 10.33723/rs.537587.

*Choi C. and Yi M. H. (2017). The Internet, R\&D Expenditure And Economic Growth, Applied Economics Letters, 25(4), 264-267; https://doi.org/10.1080/13504851.2017.13-16819.

Cohen, L., Manion, L., \& Morrison, K. (2007). Research Methods in Education, Vol2 Methods 2 Specific methods (Sixth Edition), New York: Routledge.

Dağyar, M. ve Kasalak, G. (2018). Eğitim Örgütlerinde Yaşanan Örgütsel Sinizmin Öncülleri ve Sonuçları Üzerine Bir Meta-Analiz Çalışması, Hacettepe Üniversitesi Eğitim Fakültesi Dergisi (H. U. Journal of Education), 33(4), 967-986; doi: 10.16986/HUJE.2018037797.

Deliktaş, A., Kabukcuoğlu, K., \& Kış, A. (2016). Hemşirelikte Meta-Analiz Uygulama Süreci: Metodolojiye Yönelik Bir Rehber, International Journal of Human Sciences, 13(1), 1906-1925.

Dinçer, S. (2014). Eğitim Bilimlerinde Uygulamalı MetaAnaliz, 1. Bask1, Ankara: Pegem Akademi.

Doğaner Gönel, F. (2016). Kalkınma Ekonomisi, 3. Bask1, Ankara: Efil Yayınevi.
Doyar, B. V. (2019). R\&D Expenditures By Field Of Science And GDP: Which Causes Which in Canada?, Economics and Business Letters 8(1), 3140.

Frascati Kilavuzu, (2002). Bilimsel ve Teknolojik Faaliyetlerin Ölçümü, Araştırma ve Deneysel Geliştirme Taramaları İçin Önerilen Standart Uygulama, OECD.

Freimane, R. and Bālina, S. (2016). Research And Development Expenditures And Economic Growth in The EU: A Panel Data Analysis, Economics and Business, 29, 5-11; doi: 10.1515/eb-2016-0016

Gedik, A. ve Üstüner, M. (2017). Eğitim Örgütlerinde Örgütsel Bağlılık ve İş Doyumu İlişkisi: Bir Meta Analiz Çalışması, E-Uluslararası Eğitim Araştırmaları Dergisi, 8(2), 2017, 41-57.

*Genç, M. C. ve Atasoy, Y. (2010). Ar\&Ge Harcamaları ve Ekonomik Büyüme İlişkisi: Panel Veri Analizi, Bilgi Ekonomisi ve Yönetimi Dergisi, V(II), 27-34.

Gumus, E. and Celikay, F. (2015). R\&D Expenditure And Economic Growth: New Empirical Evidence, Margin-The Journal Of Applied Economic Research 9: 3 (2015), 205-217, Sage Publications Los Angeles/London/New Delhi/Singapore/ Washington DC; DOI: 10.1177/0973801015579753.

Gülmez A. ve Yardimcioğlu, F. (2012). OECD Ülkelerinde Ar-Ge Harcamaları ve Ekonomik Büyüme İlişkisi: Panel Eşbütünleşme ve Panel Nedensellik Analizi (1990-2010), Maliye Dergisi, 163, 335-353.

Güneş, H. (2019). Ar-Ge Harcamaları İle Ekonomik Büyüme İlişkisi: OECD Ülkeleri İçin Panel Veri Analizi, Sakarya İktisat Dergisi, 8(2), 160-176

Hong, Jae-pyo (2017). Causal Relationship Between ICT R\&D Investment And Economic Growth In Korea, Technological Forecasting \& Social Change 116, 70-75.

Inekwe, J. N. (2015). The Contribution Of R\&D Expenditure To Economic Growth In Developing Economies, Soc Indic Res 124, 727-745.

İğdeli, A. (2019). Ar-Ge ve Eğitim Harcamalarının Ekonomik Büyüme Üzerindeki Etkisi: Türkiye Örneği, MANAS Sosyal Araştırmalar Dergisi, 8 (3), 2517-2538; DOI: 10.33206/mjss.520848

İspiroğlu, F. ve Kılıç, M. (2019). Araştırma-Geliştirme Harcamaları ve Ekonomik Büyüme İlişkisi: Yükselen Piyasalar Ekonomileri İçin Bir Uygulama, Anemon Muş Alparslan Üniversitesi Sosyal Bilimler Dergisi 7(2), 255-263.

Jones, C. I. ve Williams, J. C. (2000). Too Much Of A Good Thing? The Economics Of Investment In R\&D, Journal Of Economic Growth, 5, 65-85.

*Kaneva, M. And Untura G. (2019). The İmpact Of R\&D And Knowledge Spillovers On The Economic Growth Of Russian Regions, Growth And Change, 50(1), 301-334.

Karadağ, E., İşçi, S., Öztekin, S., \& Anar, S. (2016). Okul İklimi ve Akademik Başarı İlişkisi: Bir Meta-Analiz 
Çalışması, İnönü Üniversitesi Eğitim Fakültesi Dergisi, 17(2), 107-122. DOI: 10.17679/iuefd.17294446.

Kılıçkap, M. (2018). Meta-Analizleri Nasıl Yorumlayalım: Türkiye'de Kardiyovasküler Risk Faktörlerine Yönelik Yapılan Meta-Analizlerin Metodolojik Açıdan Değerlendirilmesi, Turk Kardiyol Dern Ars, 46(7), 624-635 doi: 10.5543/tkda.2018.46062.

Kibritçioğlu, A. (1998). İktisadi Büyümenin Belirleyicileri ve Yeni Büyüme Modellerinde Beşeri Sermayenin Yeri, AÜ Siyasal Bilgiler Fakültesi Dergisi, 53(1-4), 207-230.

Kokko, A., Tingvall, P. G. and Videnord, J. (2015). The Growth Effects Of R\&D Spending In The EU: A Meta-Analysis. Economics: The Open-Access, Open-Assessment E-Journal, 9 (2015-40): 1-26.

Liu, C. and Xia, G. (2018). Research On The Dynamic Interrelationship Among R\&D Investment, Technological Innovation, And Economic Growth In China, Sustainability, 10/4260, 1-19; doi:10.3390/su10114260.

Lucas, R. E. (1988). On The Mechanics Of Economic Development, Journal Of Monetary Economics 22, $3-42$.

Romer, Paul M. (1990). Endogenous Technological Change, Journal Of Political Economy, V. 98(5), 71-102.

*Sokolov-Mladenović, S., Cvetanović, S. And Mladenović, I. (2016). R\&D Expenditure And Economic Growth: EU28 Evidence For The Period 2002-2012, Economic Research-Ekonomska Istraživanja, 29(1), 1005-1020.

Solow, R. M. (1956). “A Contribution To The Theory Of Economic Frowth", The Quarterly Journal of Economics, 70(1), 65-94.

*Song, X., Zhou, Y. and Jia W. (2019). How Do Economic Openness And R\&D Investment Affect Green Economic Growth?-Evidence From China, Resources, Conservation \& Recycling 146, 405-415.
Swan, T. W. (1956). "Economic Growth And Capital Accumulation", Economic Record, 32(2), 334-361.

Szarowská, İ. (2016). Impact Of Public R\&D Expenditure On Economic Growth in Selected EU Countries, 9th International Scientific Conference "Business and Management 2016”, 1-9, Vilnius, Lithuania.

Tuna, K. Kayacan, E. ve Bektaş, H. (2015). The Relationship Between Research \& Development Expenditures and Economic Growth: The Case of Turkey, Procedia - Social and Behavioral Sciences $195,501-507$.

Türesin Tetik H., Oral Ataç, L. ve Köse, S. (2018). Psikolojik Sermaye İle İş Doyumu ve Performans İlişkisi: Türkiye'de Yapılan Araştırmalar Üzerinden Bir Meta Analizi, Atatürk Üniversitesi İktisadi ve Idari Bilimler Dergisi, 32(2).

*Ünal, B. (2018). OECD Ülkelerinde Arge Ekonomik Büyüme İlişkisi Panel Ardl Analizi, Marmara Üniversitesi Sosyal Bilimler Enstitüsü, Ekonometri Anabilim Dalı, Ekonometri Bilim Dalı, Yüksek Lisans Tezi, İstanbul.

Sun, X., Wang, Y. \& Li, M. (2016). The İnfluences Of Different R\&D Types On Productivity Growth In OECD Countries, Technology Analysis \& Strategic Management, 28(6), 651-663, DOI: 10.1080/09537325.2015.113-0806.

Yazgan \&Yalçınkaya (2018). The Effects Of Research And Development (R\&D) Investments On Sustainable Economic Growth: Evidence From OECD Countries (1996-2015), Review Of Economic Perspectives Národohospodářský Obzor 18(1), 3-23, DOI: 10.1515/revecp-2018-0001

*Yıldırım, H., Akkılıç, M. E. ve Dikici, M. S. (2018). ArGe Harcamalarının Ekonomik Büyüme ve Dış Ticaret Dengesi Üzerindeki Etkisi: G-20 Ülkeleri Üzerine Bir Uygulama, International Review Of Economics Management, 6 (2), 43-58. 